This is a self-archived version of an original article. This version may differ from the original in pagination and typographic details.

Author(s): $\begin{aligned} & \text { Husso, Marita; Notko, Marianne; Virkki, Tuija; Holma, Juha; Laitila, Aarno; Siltala, } \\ & \text { Heli }\end{aligned}$

Title: Domestic Violence Interventions in Social and Health Care Settings : Challenges of Temporary Projects and Short-Term Solutions

Year: 2021

Version: Accepted version (Final draft)

Copyright: @ 2020 SAGE Publications

Rights: In Copyright

Rights url: http://rightsstatements.org/page/InC/1.0/?language=en

Please cite the original version:

Husso, M., Notko, M., Virkki, T., Holma, J., Laitila, A., \& Siltala, H. (2021). Domestic Violence Interventions in Social and Health Care Settings : Challenges of Temporary Projects and ShortTerm Solutions. Journal of Interpersonal Violence, 36(23-24), 11461-11482.

https://doi.org/10.1177/0886260519898438 


\section{Domestic Violence Interventions in Social and Health Care Settings: Challenges of Temporary Projects and Short-Term Solutions}

\section{Marita Husso, Marianne Notko, Tuija Virkki, Juha Holma, Aarno Laitila, and Heli Siltala}

\section{Abstract}

Social welfare service and health care providers are in a key position to implement successful domestic violence (DV) interventions. However, it is known that DV intervention and prevention work is often lacking in coordination and continuity. In addition, the limited resources, hectic work pace, and changing practices negatively affect the development of successful ways to prevent and intervene in DV. This qualitative study involving 11 focus groups, composed of social welfare and health care professionals $(n=51)$ in a midsized Finnish hospital, examined the challenges and possibilities within DV interventions and the adoption of good practices produced by a DV intervention development project funded by the European Union (EU). The results show that short-term development projects, amid the pressure of limited time and resources, encounter serious challenges when applied to wicked and ignored problems, such as DV. Developing successful violence intervention practices requires a broad understanding of the challenges that rapid 
development projects present to professionals and social welfare service and health care practices at the organizational level. Hence, the implementation of good practices requires continuity in managerial and organizational support, distribution of information, documentation of DV, awareness raising, education, training, and agreement on basic tasks and responsibilities. Otherwise, the failure to continue development work derails the results of such work, and short project durations lead to unnecessary work and the need to reinvent temporary work practices time and again. Short-term interventions provide inefficient solutions to the problem of $\mathrm{DV}$, and a built-in organizational structure can prevent the misuse of organizational and human resources.

\section{Keywords}

domestic violence, intervention research, short-term development projects, temporary work practices, domestic violence documentation 


\section{Domestic Violence Interventions in Social and Health Care Settings: Challenges of Temporary Projects and Short-Term Solutions}

Domestic violence (DV) is a serious social welfare and public health concern. Since the end of the 1970s, awareness of violence in intimate relationships has been increasing in Western countries. One important outcome of this raised awareness is that DV has started to be perceived as a public, rather than private, problem. DV became part of global social policy when it received the acknowledgment of the United Nations. This new recognition occurred owing to pressure by feminist groups, and DV is increasingly being recognized as a human rights violation and a welfare issue in diverse settings because many countries lack such recognition or mechanisms to address the issue (Hester, 2005; Virkki, 2017).

In comparison with other Western, and especially Nordic, countries, Finland is an exception in many regards concerning combating violence. Although Finland has been a pioneer of gender equality in politics, education, employment, and welfare services, responses to DV have occurred only since the 1990s (Clarke, 2011; Corradi \& Stöckl, 2016; Kantola, 2006; Virkki, 2017). In addition, statistics indicate that the overall number of homicides in Finland is high in comparison with Western 
European and other Nordic countries. According to Finnish homicide statistics from the period 2010 to $2017,60 \%$ of adult female victims of homicide have been killed by a spouse, companion, or ex-companion (Lehti, 2018). Furthermore, the results of a European Union (EU)-wide survey on violence against women (European Union Agency for Fundamental Rights, 2015) show that Finland is the EU's second most violent country for women.

DV has a notorious impact on well-being. The consequences are often traumatizing, marginalizing, and lingering. DV leads to mental and physical illnesses and human suffering, and bears significant costs for police, the judicial system, and the health care and social welfare service system (Campbell, 2002; Ellsberg, 2015; European Institute for Gender Equality, 2014; Husso et al., 2017a; Piispa \& Heiskanen, 2000; Virkki et al., 2015; World Health Organization, 2013).

Research has shown that people seek help for injuries caused by DV and symptoms related to it mainly through social welfare and health care services. Thus, social welfare service and health care providers could play a key role in identifying victims of DV and in helping them, but intervention in violence is rare. Several studies have reported that social welfare service and health care professionals do not ask their clients about violence sufficiently 
and do not recognize when violence has been perpetrated even in cases where signs of physical violence are clearly visible (Bacchus et al., 2003; Husso et al., 2012; Krug et al., 2002; Lavis et al., 2005; Piispa et al., 2006; Robinson \& Spilsbury, 2008). According to research, both recognition of the existence of DV and interventions in cases of DV are lacking, and there is an urgent need for training and education of health care and social welfare professionals on DV in Finland (Husso et al., 2012; Leppäkoski et al., 2014; Niklander et al., 2019; Nikupeteri, 2017). Niemi-Kiesiläinen (2004) compared the number of homicides and domestic alerts and reports of offenses to police in Finland, Sweden, and the United States. She concluded that the main problem in Finland has not been the number of violent offenses but the lack of intervention, which then allows the violence to continue. This has led to high mortality rates, multifaceted health problems, and lingering vicious circles of violence.

Social welfare and health care workers not only have difficulties in recognizing the consequences of violence and the traumas that it causes but also struggle to understand what they see as the passive behavior of victims of violence. Often, victims' depression or inability to solve violent situations is considered the cause of violence rather than the obvious consequence of violence (Dichter \& Rhodes, 2011; Koistinen \& Holma, 2015). International research on the topic has also shown that 
perceptions of, and attitudes toward, DV often hinder interventions in violence (Friedman \& Loue, 2007; Keeling \& Fisher, 2015; Pratt-Eriksson et al., 2014; Ramsay et al., 2012). Yet previous research indicates that having encountered violence among family or friends may increase the quality of care that welfare professionals provided in violence-related cases. While personal experiences of violence are common among welfare professionals, interestingly, these experiences do not seem to necessarily generate empathic responses toward victims (Bracken et al., 2010; Christofides \& Silo, 2005).

Understandings of DV and attitudes toward it affect people's behavior and organizational practices; they also affect the organization of social welfare services and decisions concerning welfare policies and legislation. Although the extent of violence and the problems that it causes have long been known, and DV has been recognized as a gendered power question, a human rights violation, and a wicked social problem, there is still a need for more effective interventions by the welfare state (Corradi \& Stöckl, 2016; Husso et al., 2017b). There is no single definitive or simple formulation of a wicked problem like DV. Wicked problems consist of a complex cluster of symptoms, causes, and consequences. In many cases, it is unclear who should solve these problems. New practices are required that combine the existing know-how and resources of relevant professional groups (Head 
\& Alford, 2015; Jordan et al., 2014; Kazdin, 2011; Rittel \& Webber, 1973).

This article presents an analysis of the challenges posed, and possibilities offered, by intervening in violence. It also looks at the adoption of good practices yielded by DV development projects from the perspective of institutional practices of what has been called a project society (Sulkunen, 2007). In addition, the article examines and discusses the problems that development projects face, following Finland's accession to the EU, in light of the number of social welfare and health care services supported by project funding having significantly increased (see Abrahamson, 2004; McGivern et al., 2018; Sulkunen, 2007).

This study was based on findings from an EU-funded research and development project called Violence Intervention in Special Health Care (VISH). The research took place in a midsized Finnish general and psychiatric hospital. The aim of VISH was to create a research-based, transnationally valid model for intervening in violence in close relationships in specialist health care and to strengthen the channels for offering help to victims, perpetrators, and families suffering from violence. We developed a project model to identify DV survivors through a set of questions and, when necessary, referred the survivors to a team of professional psychiatric nurses and a social worker. The purpose 
of the project was to identify as many survivors of violence as possible and provide them with the needed support from the hospital or its affiliated networks. The hospital was a good research site because it is part of the Finnish universal public health system and, thus, the patients come from diverse backgrounds, which translates to maximal variation in terms of socioeconomic status, race, ethnicity, language, nationality, sex, gender identity, sexual orientation, religion, geography, ability, and age.

VISH was an exceptionally large public-sector research and development project in the Finnish context, and no comprehensive projects had previously been designed specifically for the social welfare and health care sector. The Ministry of Social Affairs and Health (2019) is responsible for the planning and steering of the prevention of domestic and intimate partner violence and, according to the current Social Welfare Act, the municipalities are obligated to provide support and services to those who have experienced violence or abuse. Despite the existence of national strategies, development projects, and good practices, there is no established DV services network in Finland. Instead, practices vary by municipality or health or social welfare unit. 
Based on the analysis of the focus group interview data collected for the project, we show how the implementation of the DV intervention service model has succeeded in practice. We discuss elements that have both hindered and eased the implementation of this service model. We ask what the critical points are in the service system in terms of intervention in DV and what the successful implementation of good practices requires for these practices to become established organizational activities.

\section{Data and Method}

We obtained the data from 11 focus group interviews with 51 special health care professionals (doctors, nurses, psychologists, and social workers). Six of these interviews were part of the pilot study units of the development project in 2009 and five were part of the same units in 2013, 2 years after the development project had ended.

As a rule, focus group interviews are guided and supported by researchers and focus on a specific topic. Typically, focus group interviews are used to elicit participants' opinions and attitudes regarding the phenomenon under discussion. The literature on focus group interviews underlines the importance of putting groups together so that they are to some extent homogeneous, 
based on the participants' prior knowledge, as this facilitates discussion (Farnsworth \& Boon, 2010; Fern, 2001; Markovà et al., 2007). We took this point into account when forming the groups. However, the study faced one limitation: As the participants were professionals who volunteered to participate in the study, the research team did not control the distribution by, for example, age, gender, or ethnicity.

During the first data collection phase in 2009, we interviewed six groups of three to seven people. The researcher and research assistant led the discussion, which concerned the issue of encountering DV during their work. The participants in these six focus groups were 30 social welfare and health care professionals: doctors, nurses, social workers, and psychologists. Four of the groups consisted of representatives of one profession only. The other two groups were multi-professional, but the participants worked in the same unit.

During the second data collection phase in 2013, there were five focus groups consisting of three to six interviewees. Two researchers from the Academy of Finland project led the discussion, which concerned both the issue of encountering DV at work and the uses and usefulness of the service model developed in the project. The five focus groups consisted of 21 health care professionals: doctors, nurses, social workers, and 
psychologists. Four of these groups consisted of representatives of one profession only. The other group consisted of social workers and psychiatric nurses who had familiarized themselves with the service model.

The second round of interviews was organized in the same units of the development project, where the questionnaire was first tested. Some of the focus group interviewees had participated in the first round of focus group interviews, but for practical reasons, such as changes in personnel, half of the participants in the second round of interviews were new personnel. The focus group discussions were guided by a set of thematic, semi-structured interview questions concerning the ways in which participants perceived their possibilities for taking professional action when encountering problems related to DV and their attitudes toward DV and people seeking help for this problem. Of special interest was whether it would be possible to follow a routine procedure for asking about DV.

The first focus group discussions, conducted in 2009, mainly concerned experiences of, and attitudes toward, DV as well as perceptions of the possibilities of using the service model developed for intervening in DV in specialized health care. During the second round of discussions, carried out in 2013, we focused on employees' experiences of using the service model 
and its usefulness. We asked about the factors that had made the implementation of the service model difficult and those that had eased the introduction of the service model; the critical points in the service system in terms of intervening in DV, identifying it, addressing it, and in guiding victims of violence to use the services provided for them; and the possibilities and challenges that the different units and representatives of different professions have for intervening in DV.

The focus group discussions were about $1 \frac{1 / 2}{\mathrm{hr}}$ in duration. They were video- and audio-recorded and then transcribed verbatim. We used qualitative content analysis as the method for interpreting the interviews and examining the data (Kohlbacher, 2006; Silverman, 2006). For ethical reasons, all identifiable references to the focus groups and interviewees have been eliminated from the quoted interviews. In the cited extracts, $\mathrm{G}$ refers to the focus group, $\mathrm{P}$ to the participant, and $\mathrm{R}$ to the researcher.

According to the World Health Organization (2001), ethical and safety recommendations for DV research and the safety of both respondents and the research team are paramount and should infuse all project decisions. In fields concerning sensitive issues, ethically appropriate research requires much more than formal assessments or ethical board reviews. Within this project, we 
followed the principles of staying alert and ethically sensitive throughout the research project and reflecting on the consequences of all actions (Notko et al., 2013). The research plans were approved by the ethical boards of the Central Finland Health Care District (2009) and the University of Jyväskylä (2013).

\section{Results}

Establishing the Service Model of Intervention in Violence as a Practice

Implementing the results of development projects is challenging. This also holds for the project under study. What emerged from the recent interviews suggests that since the 2009-2010 pilot study period, in which the five units participating the project, the use of the service model has, in all but one unit, declined or stopped altogether. This happened even though all employees participating in the project recognized the model as a good working model, and it received the organizations' official approval as a routine practice. Furthermore, the model was included in the organizations' procedure guidelines as well as national guidelines to be adopted as a policy and procedure for identifying and responding to DV in health care. However, some 
of the second-round interviewees, half of whom were new and half of whom were old employees, had not familiarized themselves with the service model at all. Some interviewees had never seen the key questions about DV to be used with clients and some were unaware of all of the practices of the developed service model.

\begin{abstract}
At least I have a feeling that it hasn't quite lasted and stayed active here if we have never even heard of it. And particularly since people here change all the time, information hasn't really been passed on. (G3P3)
\end{abstract}

The data from these interviews show that one of the major challenges of the project concerns the responsibility for disseminating information and informing personnel about the existing practices. In some units, the personnel knew about the service model, but its use was moderate or variable, depending on the person on shift.

Well, it's quite familiar, but I must say that, in practice, I have not really had much to do with it other than I've seen that the questions have been or have not been asked. Only once have I myself asked these questions. (G1P3)

In one of the six pilot study units, the interviewees considered the service model an essential part of their work. This unit contained one employee, who, from the outset of the project, had taken responsibility for disseminating information on the project and 
familiarizing new employees with the model. This employee had also managed to convince other workers of the project's importance and persuade them to take responsibility for the continuation of the service model. Going through the key questions and instituting further measures, required due to the experiences of violence revealed in the answers to the key questions, had become a normal, routine-like practice in this unit:

In this unit, it's really systematic . . . perhaps not with all of us, but the situations don't always allow you to ask the questions (about violence), and it's not wise in all situations, either. But it's daily. (G1P4)

When asked whether the reporting of violence had diminished or stopped in all but this one unit, the answers indicated that the number of reported incidents of violence had significantly declined. Consequently, the number of clients referred to the team of professionals specialized in working with violence had decreased significantly since the piloting of the service model and the end of the development project:

G5R2: Why did the number of contacts with the DV specialist team decline after the project finished?

G5P4: I think it's about asking the questions, about addressing the topic.

G5P6: We did receive then - perhaps a few years ago — clients were advised to contact our team. And since then, there's been a clear drop in the number of contacts.

G5P4: I would say it's tied to people not asking about violence so systematically anymore. 
G5P4: Yes, at the beginning, there were some serious cases of violence, incidents that had just taken place, and we were involved, but not so much anymore. It's as if they vanished somewhere.

It seems that the decline in the number of questions asked about violence and addressing violence, or stopping to ask these questions at all, resulted in a significant amount of violence being concealed from employees.

Simultaneously, in many situations, the services provided by the DV specialist team and expertise in one's own unit were not being utilized. Asking about violence, going through the key questions, and reporting the results — or not reporting them — have long-term societal consequences as written documents are significant generators of the social reality. Undocumented phenomena vanish from sight and, thus, cease to exist both as phenomena and as parts of the organizational memory (Ferraris, 2013). This has an impact not only on structural solutions for organizing services and on borderline negotiations and prioritizations within organizations but also on individuals', such as employees' and clients', perceptions and experiences of such phenomena as violence and its significance, seriousness, prevalence, and importance as a health issue and a threat to welfare. 


\section{Problems With Implementation}

The interviewees considered the developed service model to be very good and, likewise, viewed addressing violence as important. However, employees in all units gave several reasons for not bringing up violence in conversations with clients and stated that going through the key questions in their particular unit was problematic. The most common obstacles to implementing the service model included a lack of suitable space, a hectic pace of work, scheduling problems resulting from shift work, and a lack of information. They also considered addressing violence and going through the key questions as difficult and a potential addition to the existing high workload:

G1P3: Often, it's like that, in general, we have a positive attitude towards this, but combining various care tasks is very difficult in itself, so asking about violence has been seen as difficult.

G2P2: Then this snowball effect begins. The number of tasks left undone keeps getting higher, so we try to keep it as low as possible. If you come here because of a flesh wound, let's take care of the wound. We ask where it happened, but we try to confine the matter within as narrow a compass as possible.

The increase in the number of tasks and matters to take care of was a general reason for not using the service model for 
intervening in violence. As the discussion continued, the interviewees most often explained not asking questions about violence by referring to work-related obstacles, such as the lack of suitable space and hectic pace of work:

G1P4: It would be easier if we didn't have to think about how, where, and when to take it up.

G1P3: Like, I was in the linen closet with this client without a chair, and all the time there was somebody at the door asking if they could come in to get some linen. There was no other place (for going through the key questions). So, I felt the first problem was the place where the questions were asked.

G2P1: I remember that one night, I had six people (who said, when asked, that they were victims of violence), and they all came before the early morning hours. It was quite hectic.

G1P4: You could say that it takes time and cigarettes; that's what it's like. Like, it's not just about us making one phone call and redirecting people. Like, you must be prepared. The pace is hectic; clients turn up every half hour, and you should already be doing something completely different.

In addition to questions of space and the hectic pace of work, the problem of matching shift work schedules and the availability of the team specialized in working with violence emerged from the interview data. The special team is available during office hours, but most violent incidents take place during evenings, nights, and weekends:

G2P1: They weren't available during weekends; that was the problem then.

G1P5: I'm afraid of the situation when this comes up in reception or during night-time-like, "Wait a minute; what 
should I do?" Particularly since the special team is not available in the evenings or at night, we're left to deal with the client. This is something I fear-like, what would I do then?

The interviewees also mentioned uncertainty about what further actions to take as one of the reasons for not broaching the subject of violence in conversations with clients. Although the health care district's database includes a chart of the services created during the development project, some interviewees did not know where to direct clients who had experienced violence or whom to contact in such cases:

G4P5: The number should be clearly visible somewhere, so that you don't have to look for it, search for it on the internet or phone the call centre or someplace else.

G4P2: I think that half my working hours are spent on calling various people and places to find numbers for redirecting clients.

G4P1: Aren't they on the development project's form-the numbers for redirecting people?

G4P4: Oh, do tell us, too.

G4P1: Are they there?

In addition to increasing their workload and encountering practical problems, such as lack of time and space, some interviewees mentioned uncertainty about the availability of help and possible need for follow-up measures as an obstacle to raising questions about violence with clients. The employees would 
prefer to receive feedback on whether a client had been redirected to further services and whether the client had received help or not:

G1P4: I think the most horrible thing is that we first ask these questions and bring up violence as an issue and promise help that the client then never receives.

G2P3: Like, we give them the tools, and when they have used them, we take them away. At times, I wondered how the matter was handled, whether anybody really intervened in it, whether the client got any help or not.

The above data show that problems in disseminating information have, in many ways and at many levels, been significant obstacles to using the service model for intervening in violence since the pilot study. According to the interviewees, in addition to information regarding the service model not being circulated between different units within the organization, and not even within units (excluding one), there has been insufficient followup with clients and victims of violence who have been redirected to the DV specialist team. Problems in distributing information and making information available to new employees have long been recognized as obstacles to the implementation of shortterm development projects. Developing organizational practices is based on multifaceted collective learning and an exchange of experiences. At different times, learning and the exchange of experiences have been understood and conceptualized in different ways. The understanding of the nature of development prevalent at any given time has also guided the research- 
development interaction in practice and, simultaneously, attitudes toward the distribution of information. Opting not to disseminate information on the results of development projects and inform new employees about existing practices continues to be a common problem for development projects. This is the case despite the fact that the devastating consequences of problems in disseminating information both within the social welfare and health care sectors and between actors in various fields and units have repeatedly been highlighted and reported (e.g., Ciborra et al., 2000; Stephan et al., 2016; Strümpel \& Hackl, 2011).

Development Project Fatigue and Changes in Attitude

In addition to discussing discrepancies in the organization of tasks and implementation of the service model for intervening in violence, and problems with the distribution of information, the interviewees clarified the challenges of coping with victims of violence or of bringing violence up in conversation with clients, such as development project fatigue. Many interviewees confessed that the biggest obstacles to asking about violence were "inside their own heads":

G1P4: At least, if I think about my own case, when we started talking about this, I had a very strong opinion against it then-like, my goodness, all the things we need to do. Like, I think that the biggest obstacle (to bringing violence up) is 
in one's own head. My case went like, at first, I strongly opposed it and right away thought, "Never in my life. This will not work out; nobody has time for this. This is downright awful; this doesn't suit us at all" . . . awful chit chat for several weeks, until I had to do it, and then my opinion changed completely.

G1P3: Like in many other things, too.

G1P4: Yes, just like that, but the biggest obstacle is there right in one's own heads. And when we had the first cases, when somebody really benefited from the discussions, I began to think about it from a different angle.

Part of the resistance to implementing the service model for intervening in violence concerns the unique quality of DV. In particular, DV between adult partners often evokes contradictory feelings. Many people still consider DV to be a private matter, which is the responsibility of those involved in it and, thus, does not warrant interference from outsiders (Husso et al., 2017c). However, opposition to new projects and practices does not always depend on their purpose or content.

In addition to the challenges posed in the present instance of encountering victims of violence, some of the resistance and negative attitudes toward projects in general can be explained by employee development project fatigue. Many employees, especially in health care, are weary of, and frustrated with, a succession of disparate development projects involving tasks that do not become established as permanent practices and, thus, do not logically advance development work. The following 
interviewees' comments show frustration with any new development projects that relentlessly follow one after the other:

G1P4: But I do think that this is a good tool, in a way, anywhere - here or in any other unit - but the thing is that the employer should understand what it means to the employees. This is it. We are the ones who have to process these things then, and it should somehow count in the resources. Like, it shouldn't be a kind of never-ending thing; like, we can't be expected to just move on: "Here's a task and the next task, and yet another task."

G1P3: I don't think that it's just about us being lazy or ineffective, because this shit keeps coming at us all the time, so at some point it reaches the limit of "no more."

The ever-expanding amount of development project work and projects that follow in seemingly endless succession have also begun to face critique in the public arena. Increasingly, these projects are referred to with negative metaphors. People talk about project fatigue, project chaos, project circus, project jungle, and project avalanche, and they refer to project development and the continuous presence of change by discussing development fatigue and becoming inured to thinking about development (McGivern et al., 2018; Santos et al., 2014). The multitude of development initiatives and the organizational chaos that ensues, as well as employee exhaustion and a tendency toward cynicism, have been labeled a problem cluster typical of our times (Abrahamson, 2004). Uncontrollability, discontinuity, and fragmentation are characteristics associated with the over- 
abundance of development projects. A lack of basic work resources and too hectic a pace of work are considered reasons for criticism of development projects.

When a busy phase ends, and employees have time and space to familiarize themselves with a development project, those tired of being forced to implement one project after another may well change their minds and attitudes. Many of the interviewees in this study stated that during the experiment, they had realized that when screening for the presence of violence, they encountered surprises. First, the screening questions did not take as much time and work as they had expected. It took only a few minutes to ask the screening questions, and clients' responses were much more positive than the interviewees had expected. Second, at the beginning of the development project, many said that they thought they would easily be able to recognize clients and patients suffering from violence. However, they reported that, contrary to their expectations, after having raised the issue of violence and asking the key questions, they noticed that victims of violence are not necessarily identifiable without asking direct questions:

Very often, the person who has faced violence is somebody you'd never think would suffer from such a problem-like, it comes as a surprise. Like, you can't really tell with everybody (G1P4). 
In addition to having to question their own assumptions, many interviewees said that they were surprised at how many clients and patients were grateful and relieved that they had been asked about violence:

G2P1: Yes, we got positive feedback, and I think that we should continue this because, underneath these small problems, when asked directly, there is a deep sorrow that causes all kinds of issues behind the facade. I remember that in one case, the client had answered the first few questions and gave a long sigh, and then asked if she could really talk to me. And she told me. And she had experienced devastating violence, really, and the process was still going on, all the time.

G2R1: Do you think it would have otherwise come up [without being directly asked about]?

G2P1: No, I don't think so.

Those who admitted that they had initially opposed the new project and bringing up violence in discussions with clients explained in the interviews that they subsequently considered the service model to be worth keeping and developing further. Many of those who had tried to implement the model hoped that their superiors would adopt a more positive and supportive attitude toward it, and they also hoped for support for it from their organizations.

G5P6: A lot of difficulties have been caused by the organization. When the project ended, there was no guidance or training, nobody you could contact about these things. It was kinda left hanging in the air, this thing. 
G5P2: It's very important that higher management is strongly committed to implementing new practices. Without their support, it doesn't work, and there was a slight problem here: not everybody was committed. The project ended and we were kinda left with nothing, really.

The ongoing implementation of good practices developed in a project requires overcoming practical problems and difficulties in the distribution of information, clear agreement on the organization of tasks and assignment of responsibilities and duties, and managerial and organizational support for changes in practices. Previous studies have shown that the possibilities for implementing practices developed in a project and changing existing practices increase as the number of people involved in the process increases. Thus, real changes in practices require the participation of both managers and workers. This process is not about the execution of a plan as such but a continuous, long-term effort to find solutions to emerging problems through collaboration. The inability to dedicate organizational resources efficiently and absence of ongoing development work easily undo the results achieved (Billet, 2016; Ciborra et al., 2000; Santos et al., 2014). In addition, there is a serious need for education on the phenomenon of DV and training to ensure that the people who provide training for professionals have access to suitable learning materials on DV to provide effective means of improving DV screening, identification, and intervention. 


\section{Conclusion}

The accumulation of projects has been perceived as the public administration's way of adapting to the strengthening of global market forces and as a means of improving the efficiency and cost-effectiveness of services and meeting the need for organizational downsizing in the spirit of New Public Management (Lægreid \& Christensen, 2007). The growing number of individual, short-term development projects has also been interpreted as a process of shifting away from a welfare state to a society that distributes the responsibilities of welfare provision more broadly and, from there, to a project-based society that tackles more limited phenomena and clearly defined problems. What characterizes these projects is that their existence is tied to achieving, within a defined period, the goals that have been set for them. However, goals in welfare services can rarely be singled out for achievability, and the need for services does not cease as a result of the action taken (Bryson et al., 2014; Hirvonen \& Husso, 2012; Kajamaa, 2011). On the contrary, welfare services are tasked with solving very complex, wicked social problems.

The service model was, and still is, considered functional and well planned, fruitfully combining existing know-how and resources. However, development projects typically suffer from two problems: their short-term duration and the interruption in the 
practical implementation of their outcomes. Most of the good practices developed during the project were not adopted after the project ended; in other words, the application of the outcome was left hanging in the air.

Problems in distributing information on the service model, both within and between units, were ultimately fatal for the service model after the project ended. Furthermore, enabling the implementation of the service model, partly owing to a lack of devolution of responsibilities and coordination of tasks, turned out to be difficult. A lack of resources and failure to reorganize basic tasks in the different units to make the service model applicable also proved to be obstacles. In the current organizational situation, among an avalanche of projects, employees' tasks must be as clearly defined as possible. In practice, when the sheer amount of work threatens to snowball uncontrollably, the most rational solution, from both the organizational and employee points of view, often seems to be excluding everything extra, including the implementation of project outcomes.

Limiting the tasks that one takes on is often a well-advised and reasonable means of survival. However, it ignores the opposite snowball effect: When, for example, violence is not taken up with clients or directly asked about, it is also not reported, documented, or archived in various databases. Consequently, undocumented incidents of violence become invisible and cease to exist both as 
phenomena and as parts of the organizational memory. The significance of reporting and archiving documents is based on their ability to generate or establish an action or task and to enable these in contexts other than their original context. Asking about violence, going through the key questions, and reporting the results - or not reporting them-have long-term consequences in present-day society, where written documents are significant generators of social reality. Undocumented phenomena vanish from sight and, thus, cease to exist both as phenomena and as parts of the organizational memory. When social welfare and health care services overlook the phenomenon of violence, the volume of violent incidents and their consequences are not understood and interventions in violence remain unimplemented (Ferraris, 2013). This affects not only structural solutions for organizing services and borderline negotiations and prioritizations within organizations but also individuals', such as employees' and clients', perceptions and experiences of such phenomena as violence and its significance, seriousness, prevalence, and importance as a health issue and a threat to welfare.

It should also be remembered that an unaccomplished intervention in violence is also economically an untenable solution. The millions of euros invested in short-term development projects, the results of which are not ultimately made use of, add up to a significant amount of money; however, 
project funding is only a drop in the ocean in comparison with the indirect and direct costs of violence to society (Decker et al., 2012; Piispa \& Heiskanen, 2000). When the implementation of development project results fails and the distribution of information is ignored, short-term projects often mean reinventing the wheel time and again. Short-term savings, which resemble robbing Peter to pay Paul, are often not the choices of individual organizations but are forced actions resulting from fiscal guidance mechanisms, which can lead to a significant waste of economic and human resources in the long run. It is also worth remembering that in addition to economic losses, violence causes a wide range of social and health problems, human suffering, and premature mortality. Developing successful violence intervention practices requires a broad understanding of the challenges that rapid development projects present to professionals and social welfare service and health care practices at the organizational level. To be able to meet these challenges, comprehensive education on DV, and how to face and intervene in violence is needed (Niklander et al., 2019). The broad interest in violence studies programs and continuous online training for identifying, preventing, and intervening in violence shows that there is an increasing demand for such education. 


\section{References}

Abrahamson, E. (2004). Change without pain. How managers can overcome initiative overload, organizational chaos, and employee burnout. Harvard Business School Press.

Bacchus, L., Mezey, G., \& Bewley, S. (2003). Experiences of seeking help from health professionals in a sample of women who experienced domestic violence. Health and Social Care in the Community, 11, 10-18. https://doi.org/ 10.1046/j.1365-2524.2003.00402.x

Billett, S. (2016). Critiquing workplace learning discourses: Participation and continuity at work. Studies in the Education of Adults, 34(1), 56-67. https://doi.org/10.1080/02660830.2002.11661461

Bracken, M. I., Messing, J. T., Campbell, J. C., La Flair, L. N., \& Kub, J. (2010). Intimate partner violence and abuse among female nurses and nursing personnel: Prevalence and risk factors. Issues in Mental Health Nursing, 31, 137-148. https://doi.org/10.3109/01612840903470609

Bryson, J. M., Crosby, B. C., \& Bloomberg, L. (2014). Public value governance: Moving beyond traditional public administration and the new public management. Public Administration Review, 74(4), 445-456. https://doi.org/10.1111/puar.12238

Campbell, J. C. (2002). Health consequences of intimate partner violence. Lancet, 359, 1331-1336. https://doi.org/10.1016/S0140-6736(02)08336-8

Christofides, N.J., Silo, Z. (2005). How nurses' experiences of domestic violence influence service provision: Study conducted in North-west province, South Africa. Nursing \& Health Sciences, 7(1), 9-14. https://doi.org/10.1111/j.14422018.2005.00222.x

Ciborra, C. U., Braa, K., Cordella, A., Dahlbom, B., Failla, A., Hanseth, O., . . . Simon, K. A. (2000). From control to drift. The dynamics of corporate information infrastructures. Oxford University Press.

Clarke, K. (2011). The paradoxical approach to intimate partner violence in Finland. International Perspectives in Victimology, 6(1), 9-19. https://www.researchgate.net/publication/304215909_The Paradoxical_Approach_to_Intimate_Partner_Violence_in_F inland

Corradi, C., \& Stöckl, H. (2016). The lessons of history: The role of the nation-states and the EU in fighting violence against women in 10 European countries. Current Sociology Monograph, 64(4), https://doi.org/10.1177/0011392116640457

671-688. 
Decker, M. R., Frattaroli, S., McCaw, B., Coker, A. L., Miller, E., Sharps, P. . . . Gielen, A. (2012). Transforming the healthcare response to intimate partner violence and taking best practices to scale. Journal of Women's Health, 21(12), 1222-1229. https://doi.org/10.1089/jwh.2012.4058

Dichter, M. E., \& Rhodes, K. V. (2011). Intimate partner violence survivors' unmet social service needs. Journal of Social Service Research, 37(5), 481-489. https://doi.org/10.1080/01488376.2011.587747

Ellsberg, M., Arango, D.J., Morton, M., Gennari, F., Kiplesund, S., Contreras, M., \& Watts, C. (2015). Prevention of violence against women and girls: what does the evidence say? The Lancet, $385(9977), \quad 15551566$. https://doi.org/10.1016/S0140-6736(14)61703-7

European Institute for Gender Equality. (2014). Estimating the costs of gender-based violence in the European Union: Report. https://eige.europa.eu/publications/

estimating-costs-gender-based-violence-european-unionreport

European Union Agency for Fundamental Rights. (2015). EUwide survey: Violence against women. Main results report. Publications Office of the European Union. https://fra.europa.eu/en/publication/2014/violence-againstwomen-eu-wide-survey-main-results-report

Farnsworth, J., \& Boon, B. (2010). Analysing group dynamics within the focus group. Qualitative Research, 10, 605-624. https://doi.org/10.1177/1468794110375223

Fern, E. F. (2001). Advanced focus group research. SAGE. https://doi.org/ $10.4135 / 9781412990028$

Ferraris, M. (2013). Documentality: Why it is necessary to leave traces. Fordham University Press.

Friedman, S. H., \& Loue, S. (2007). Incidence and prevalence of intimate partner violence by and against women with severe mental illness. Journal of Women's Health, 16, 471-480. https://doi.org/10.1089/jwh.2006.0115

Head, B. W., \& Alford, J. (2015). Wicked problems: Implications for public policy and management. Administration \& Society, $47(6)$,

$10.1177 / 0095399713481601$

711-739.

Hester, M. (2005). Transnational influences on domestic violence policy and action-Exploring developments in China and England. Social Policy \& Society, 4(4), 447-456. https://doi.org/10.1017/s1474746405002630

Husso, M., Virkki, T., Notko, M., Holma, J., Laitila, A., \& Mäntysaari, M. (2012). Making sense of domestic violence intervention in professional health care. Health and Social Care 
in the Community,

https://doi.org/10.1111/j.1365-2524.2011.01034.x

Husso, M., Virkki, T., Notko, M., Hirvonen, H., \& Eilola, J. (eds) (2017a). Interpersonal violence. Differences and connections. London, Routledge.

Husso, M., Virkki, T., Notko, M., Hirvonen, H., \& Eilola, J. (eds) (2017b) A Spatial-temporal, intersectional and institutional approach to interpersonal violence. In Husso, Marita, Virkki, Tuija, Notko, Marianne, Hirvonen, Helena \& Eilola, Jari (eds) Interpersonal Violence. Differences and Connections. London, Routledge, 1-13.

Husso, M., Hirvonen, H., \& Notko, M. (2017c) From rejection to understanding: towards a synthetic approach to interpersonal violence. In Husso, M., Virkki, T., Notko, M., Hirvonen, H., \& Eilola, J. (eds) Interpersonal Violence. Differences and Connections. London, Routledge, 227-234.

Jordan, M. E., Kleinsasser, R. C., \& Roe, M. F. (2014). Wicked problems: Inescapable wickedity. Journal of Education for Teaching, 40(4),

415-430. https://doi.org/10.1080/02607476.2014.929381

Kajamaa, A. (2011). Unraveling the helix of change: An activitytheoretical study of health care change efforts and their consequences. University of Helsinki.

Kantola, J. (2006). Feminists Theorize the State. Basingstoke and New York, Palgrave Macmillan.

Kazdin, A. E. (2011). Conceptualizing the challenge of reducing interpersonal violence. Psychology of Violence, I (3), 166-187. https://doi.org/10.1037/a0022990

Keeling, J., \& Fisher, C. (2015). Health professionals' responses to women's disclosure of domestic violence. Journal of Interpersonal Violence, 30(13), 2363-2378. https://doi.org/10.1177/0886260514552449

Kohlbacher, F. (2006). The use of qualitative content analysis in case study research. Forum Qualitative Sozialforschung/Forum: Qualitative Social Research, 7(1), $1-30$.

Koistinen, I., \& Holma, J. (2015). Finnish health care professionals' views of patients who experience family violence. SAGE Open, 5 (1), 1-10, https://doi.org/10.1177/2158244015570392

Krug, E. G., Dahlberg, L. L., Mercy, J. A., Zwi, A. B., \& Lozano, R. (2002). World report on violence and health. World Health Organization.

https://apps.who.int/ iris/bitstream/handle/10665/42495/9241545615_eng.pdf; sequence $=1$

Lægreid, P., \& Christensen, T. (Eds.). (2007). Transcending new public management: The transformation of public sector reforms 2007. Ashgate Publishing. 
Lavis, V., Horrocks, C., Kelly, N., \& Barker, V. (2005). Domestic violence and health care: Opening Pandora's box-Challenges and dilemmas. Feminism and Psychology, 15(4), 441-460. https://doi.org/10.1177/0959-353505057618

Lehti, M. (2018). Henkirikoskatsaus 2018 [Homicide report 2018]. Institute of Criminology and Legal Policy, University of Helsinki.

Leppäkoski, T., Flinck, A., \& Paavilainen, E. (2014). Assessing and enhancing health care providers' response to domestic violence. Nursing Research and Practice, 2014, Article 759682. https://doi.org/10.1155/2014/759682

Markovà, I., Linell, P., Grossen, M., \& Orvig, A. S. (2007). Dialogue in focus groups: Exploring socially shared knowledge. Equinox.

McGivern, G., Dopson, S., Ferlie, S., Fischer, M., Fitzgerald, L., Ledger, J., \& Bennett, C. (2018). The silent politics of temporal work: A case study of a management consultancy project to redesign public health care. Organization Studies, 39(8), 10071030. https://doi.org/10.1177/0170840617708004

Ministry of Social Affairs and Health. (2019). Combatting domestic and intimate partner violence. https://stm.fi/en/combating-domestic-violence

Niemi-Kiesiläinen, J. (2004). Rikosprosessi ja parisuhdeväkivalta [Criminal procedure and intimate partner violence]. Helsinki, WSOY.

Niklander, E., Notko, M., \& Husso, M. (2019). Intervening in domestic violence and training of professionals in social services and health care and the police: Evaluation of the EPRAS project. Helsinki, National Institute for Health and Welfare. Retrieved from http://urn.fi/URN:ISBN:978-952343-413-4

Nikupeteri, A. (2017). Professionals' critical positionings of women as help-seekers: Finnish women's narratives of helpseeking during post-separation stalking. Qualitative Social Work, 16(6), 793-809. https://doi.org/10.1177/ 1473325016644315

Notko, M., Jokinen, K., Malinen, K., Harju-Veijola, M., Kuronen, M., \& Pirskanen, H. (2013). Encountering ethics in studying challenging family relations. Families, Relationships and Societies, 2(3), https://doi.org/10.1332/204674313X665085

Piispa, M., \& Heiskanen, M. (2000). The price of violence: The costs of men's violence against women in Finland. Statistics Finland.

Piispa, M., Heiskanen, M., Kääriäinen, J., \& Siren, R. (2006). Violence against women in Finland. National Research Institute of Legal Policy. 
Pratt-Eriksson, D., Bergbom, I., \& Lyckhage, E. D. (2014). Don't ask don't tell: Battered women living in Sweden encounter with healthcare personnel and their experience of the care given. International Journal of Qualitative Studies in Health and Well-Being, 9, Article 23166. https://doi.org/10.3402/qhw.v9.23166

Ramsay, J., Rutterford, C., Gregory, A., Dunne, D., Eldridge, S., Sharp, D., \& Feder, G. (2012). Domestic violence: Knowledge, attitudes, and clinical practice of selected UK primary healthcare clinicians. British Journal of General Practice, 62(602), e647-e655. https://doi.org/10.3399/bjgp12x654623

Rittel, H., \& Webber, M. (1973). Dilemmas in a general theory of planning. Policy Sciences, 4, 155-169. https://doi.org/10.1007/bf01405730

Robinson, L., \& Spilsbury, K. (2008). Systematic review of the perceptions and experiences of accessing health services by adult victims of violence. Health and Social Care in the Community, 16(1), 16-30. https://doi.org/10.1111/j.13652524.2007.00721.X

Santos, C., Santos, V., Tavares, A., \& Varajão, J. (2014). Project management success in health-The need of additional research in public health projects. Procedia Technology, 16, 1080-1085. https://doi.org/10.1016/j.protcy.2014.10.122

Silverman, D. (2006). Interpreting qualitative data: Methods for analysing talk, text and interaction. SAGE.

Stephan, U., Patterson, M., Kelly, C., \& Mair, J. (2016). Organizations driving positive social change: A review and an integrative framework of change processes. Journal of Management, 42(5), 1250-1281. https://doi.org/10.1177/ 0149206316633268

Strümpel, C., \& Hackl, C. (2011). The Breaking the Taboo projects-Raising awareness of, and training staff in, community health and care services on violence against older women within families. The Journal of Adult Protection, 13(6), 323-335. https://doi.org/10.1108/14668201111194230

Sulkunen, P. (2007). Re-inventing the social contract. Acta Sociologica, 50(3), 325-333. https://doi.org/10.1177/0001699307080939

Virkki, T. (2017). At the interface of national and transnational: The development of Finnish policies against domestic violence in terms of gender equality. Social Sciences, 6 (1), 31. https://doi.org/10.3390/socsci6010031

Virkki, T., Husso, M., Notko, M., Holma, J., Laitila, A., \& Mäntysaari, M. (2015). Possibilities for intervention in domestic violence: Frame analysis of health care professionals' attitudes. Journal of Social Service Research, 41(1), 6-24. https://doi.org/10.1080/01488376.2014.917449 
World Health Organization. (2001). Putting women first: Ethical and safety recommendations for research on domestic violence against women. https://www.who.int/gender/violence/womenfirtseng.pdf

World Health Organization. (2013). Responding to intimate partner violence and sexual violence against women: WHO clinical and policy guidelines. https://apps.who.int/iris/bitstream/handle/10665/85240/97892 41548595_eng.pdf; sequence=1 